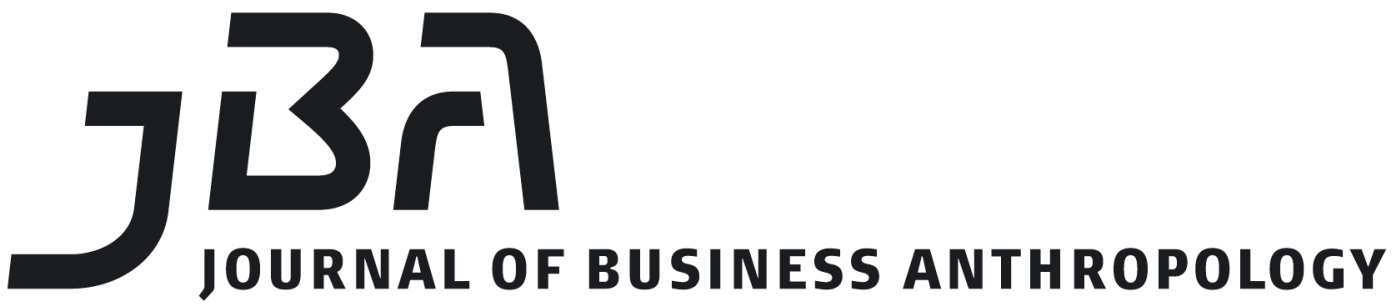

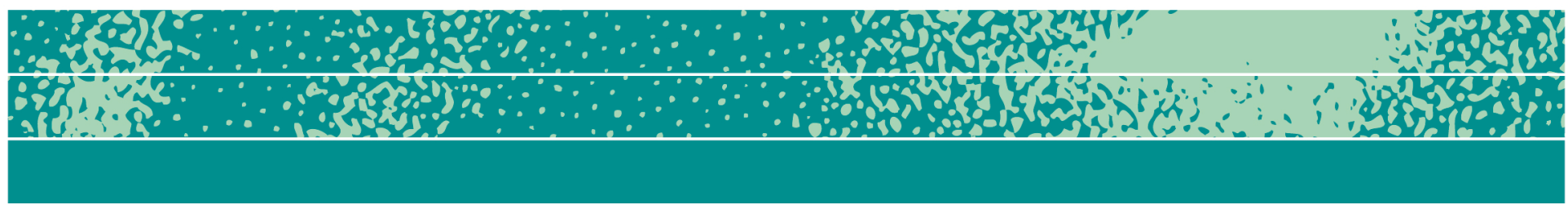

Millennial \& Post-millennial Perspectives

\section{Why Businesses and Consumers Need Us}

Elisabeth Powell

\section{Setting the Stage}

"I majored in anthropology because I want to go into business," says

Page 1 of 13 virtually no one. I certainly didn't. Anthropology is interesting, but irrelevant. Everyone knows that. When I decided to major in anthropology, I did so acknowledging that I was sacrificing post-graduate job opportunities in order to pursue my academic passion. What would an anthropologist do in business, anyways? I saw no possible role for totems, liminality or kinship in the modern business world.

JBA 8(1): 126-138 Spring 2019

(C) The Author(s) 2019 ISSN 2245-4217

www.cbs.dk/jba

However, my assumptions about the relevance and value of anthropology in business were fundamentally destabilized when I embarked upon my Princeton Senior Thesis studying academic anthropologists employed in business contexts. I had absolutely no clue that anthropologists even existed in business. And, that their anthropological identities and studies might actually add unique value was stunning to me.

Still, though, I wasn't quite convinced that anthropology would be relevant in my business journey. As I interviewed for post-graduate jobs, I couldn't shake the twinge of regret over my decision to stray from the safer, clearly defined route in economics. When speaking with potential employers, I found myself apologizing for my anthropology education, or 
attempting to avoid the topic altogether. In many ways, I felt like an alien as an anthropologist trying to land in the business world. However, five years of work experience at premier innovation, consumer research and brand strategy consultancies tackling challenges for clients including Uber, Apple, Hilton, Diageo, Estee Lauder and Google have proven me completely wrong.

In this column, I hope to share why and how an education in anthropology can and does add unique value in the business world - first from my thesis research interviewing twenty anthropologists in business, and then reflecting on my own post-graduate business experience. I have been converted from a skeptic of, to an evangelist for, anthropologists in business. In fact, I contend that we critically need anthropologists in business if we want to build a more empathetic, connected and humane world. Frankly, I got lucky that I fell into anthropology. However, I hope for a future where students seek anthropology with intentionality because they know that anthropology is invaluable in business and in any pursuit involving an understanding of human beings. If your interest is piqued, I hope you'll read on.

\section{Discovering Anthropology}

If someone had told me that I would graduate from Princeton University with a Bachelor of Arts degree in anthropology, I would have thought she was crazy. I had never even heard of anthropology before college. While I wasn't sure what I wanted to do when I graduated or what I wanted to major in, I knew that I'd need to sustain myself economically after graduation. There was no safety net. Having excelled at math in high school and figuring that I would eventually pursue something in business, economics seemed like the most logical, practical, and relevant major. To confirm my interest and to satisfy the economics major prerequisites, I took Introduction to Microeconomics and Introduction to Macroeconomics during my freshman year.

Unlike my purposeful pursuit of economics, I stumbled into anthropology. Anthropology Professor Alan Mann was offering Foodways: Biocultural Aspects of the Human Diet. Having been president of my high school's culinary society and generally interested in food and health, I was excited about the opportunity to take a Princeton course on the topic. I had no idea what anthropology even meant, but I decided that the course was too compelling to pass up. I remember getting to the classroom on the first day and fearing I had gone to the wrong room: a glass case along one wall was filled with dozens of skulls. Unnerved but intrigued, I decided to stay put. I am glad that I did!

I ended up loving the cross-cultural and evolutionary approach to the human diet. I had never thought to consider questions that seemed so basic and fundamental as: "What is food?"; "What is health?"; "What is the 
optimal human diet?" The answers to these questions were not as clearcut and obvious as I had imagined. Moreover, Professor Mann was absolutely phenomenal - so abundantly enthusiastic about the subject matter and about each of his students.

In fact, I had such an extraordinary experience in Professor Mann's course that I decided to take another anthropology course he was teaching during the summer: Modern Human Origins. The course was taught in Bordeaux, France, and conveniently satisfied my lab science requirement. In France, I learned about key facts and debates around early modern human origins. I visited field sites, toured caves with stunning cave paintings, and actually excavated at Les Pradelles, an archaeological site in Marillac, France. I remember my sense of awe and accomplishment when I successfully excavated a reindeer mandible from tens of thousands of years ago.

Back on campus for my sophomore year, I stayed on track with my prerequisites for economics. Although I had truly enjoyed my courses in anthropology thus far, I still was not seriously considering anthropology as a major. I could see no relevance to my own life. They were really interesting but seemed useless for someone interested in more conventional pathways to independence and life beyond the "Orange Bubble." Certainly, I believed, for someone who ultimately wanted to end up in business, knowing about supply and demand and how to run regressions would be far more practical than knowing about bones and far-off villages.

To balance my Statistics and Data Analysis for Economics course, I decided to take another anthropology course called Desire and Repression: Economic Anthropology and American Pop Culture taught by Professor Carolyn Rouse. Again, I took the course because it sounded very interesting - not because I thought it would necessarily be practical. However, I remember having an eye-opening moment on one of the first days of the course after Professor Rouse assigned us to read The World of Goods (1979) by Mary Douglas and Baron Isherwood.

Douglas and Isherwood problematized some of the fundamental premises of classical economic theory that I had been taught and uncritically learned as "truth" in my introductory economics courses. They challenged the assumption made in economic theory that economic activity can be analyzed on the basis of individual actors making rational choices to maximize utility based on consistent and stable preferences. Consumption choices depended upon income and prices, assuming "tastes" to be given.

As an explanatory model for consumer behavior, Douglas and Isherwood were not convinced. They pointed out that traditional economic theory fails to explain why people want goods. Professor Rouse taught us that an anthropological approach would attend to "individuals" 
only as deeply embedded in sociocultural contexts. Therefore, "economic" activity cannot be understood by bracketing off the social and cultural. Rather, all economic activity is also social activity, laden with culturally specific meanings and norms - and only intelligible if one understands the sociocultural, economic and political context in which they are made meaningful.

It was a revelation to me that there were approaches to studying economic activity other than from within a traditional economics department. I had thought economics was "law" regarding anything related to economic activity. I wondered more about the drivers of economic activity, but I did not find explanations in my economics classes. I wished for an economic anthropology major, but I could not find anything of the sort at Princeton. There were certainly no anthropologically oriented courses taught within the Economics Department.

So, when Anthropology Professor Rena Lederman offered Economic Experience in Cultural Context, I eagerly enrolled in the course. During that semester, I was surprised to learn that anthropologists studied subjects like the marketing of Coca Cola (Miller 1998a), the advertising industry, and other aspects of production and consumption that I was familiar with in my own non-academic life. I also discovered that anthropological theories explaining economic principles in far-off communities could actually help me to understand my own economic activity. This second discovery came as a result of Professor Lederman's expectation that we keep a journal throughout the semester connecting our own experiences to course readings. I was shocked at how applicable and revelatory the academic work was to help explain my own practices that I usually did not consider critically.

Despite my initial conceptions of anthropology as interesting but largely irrelevant to my own life, it seemed that anthropological work could actually provide insights into my own behavior!

\section{Choosing a Major}

At the end of my sophomore year, it was time to declare my major. Economics was a major that "made sense" for someone expecting to go into business. I believed that it would add more credibility to my brand in the eyes of potential employers than would anthropology. Even among Princeton students, there was a general consensus that economics was more rigorous, legitimate and practical than anthropology. Economists use numbers, calculations and graphs to understand economic activity; anthropologists study liminality and totems in remote villages, or they dig up our ancestors' bones to understand more about humanity.

Yet the mechanical, individualistic, and narrowly quantitative 
approach taken in economics bored me. I was drawn to the focus on the broader sociocultural context that was a core aspect of anthropological study. The idea that human behavior is only intelligible in context made more sense to me than the isolated view taken by economists using graphical and numerical models. I loved how the seemingly simple questions anthropologists asked often led to unexpected complexity and to the challenging of basic assumptions. Anthropology is unique and liberating in that it is not tied to a particular subject matter; rather, it is an analytical perspective that can be applied to better understand human behavior in any context. Moreover, I had established meaningful relationships with many of my anthropology professors, who I knew would guide me through my independent work and enrich my education.

However, I still had many reservations about majoring in anthropology. What do you do with an anthropology major? How do you explain that to a potential employer? I was worried about the smirks and eyebrow raises I was sure to get when I told people I was studying anthropology. I got them from my classmates and friends when we discussed our thinking about majors. Economics seemed a safer and more logical choice for someone who would end up in business.

I recall having lunch with one of my economics professors from freshman year, whom I had kept up with and whose opinion I respected. As I described to him my indecision between economics and anthropology, I remember him telling me a story about his own daughter. When she was in school, she had told him that she planned to major in anthropology. Though he did not discourage her from doing so, he told me how relieved he was when she changed her mind. From his perspective, anthropology was "fluffy," "inconclusive" and "unemployable." His dismissiveness reinforced my fear that anthropology might be interesting but ultimately would not be valuable in the business world. Indeed, knowledge of the Nuer in the Sudan, of kinship among the !Kung, and of Kula ring exchange systems hardly seemed relevant to business.

However, in weighing my decision, I also met with another former professor and Deputy Dean of the College, Clayton Marsh. Based on the passion I expressed for my anthropology experiences, classes and professors, and my genuine interest in the approaches taken in those courses, he advised me to pursue anthropology. I conveyed to him my concerns about employment, but he told me that my career would fall into place.

My parents reiterated that they sent me to Princeton in order to get a phenomenal education and to discover and immerse myself in what I love, not in what I necessarily thought I was "supposed" to do. All of them encouraged me to major in anthropology, though none did so citing that it would make finding employment after Princeton any easier. So, 
having no idea how my decision would impact my career options coming out of Princeton (though I expected it to limit them), I decided to major in anthropology.

Entering my senior year, I did not regret my decision at all - from an academic perspective. As an educational pursuit, anthropology was a fabulous fit for me. However, I could no longer ignore the daunting questions: What next? What can I do with an anthropology degree? Or, how can I at least spin it as relevant to potential employers?

\section{My Summer Intern Experiences}

Fortunately, I had some work experience to put on my resume. Following my father's advice to immerse myself in something I love or to fight something I hate, I interned as a volunteer with the American Cancer Society. I had no preconceived notion of how it might fit into an ultimate career path or a job after graduation. I just hated cancer and was passionate about fighting it.

As part of my work with the Distinguished Events team, I helped to develop the first ever awareness and fundraising event for the LGBTQ+ community in New York. My team had to first understand the community in order to be able to create an event that would be relevant and enticing for them. Our "research" consisted of several conversations with LGBTQ+ community members and combing through community blogs and news outlets. Though this research was far more limited in time and scope, it still reminded me of the work I had been exposed to in my anthropology courses so far, where anthropologists went out to study and understand a particular community.

I was surprised to find that I was again referencing my academic studies in anthropology during my next two summer internships. While working as a cosmetics buyer for a multinational retailer, there was a major strategic focus on capturing the growing "Hispanic consumer" segment (problematic terminology in and of itself). I remember being surprised that in meetings, non-Hispanic buyers were making product selections for the idealized "Hispanic consumer." To my knowledge, they never studied Hispanic consumers or made efforts to better understand the Hispanic culture, values, and buying behaviors. They did not even understand that many unique sub-cultures and shared experiences fall within this fictional "Hispanic consumer" segment. Rather, they made decisions based on stereotypes.

Then again, I was consistently reminded of anthropology while interning on the global marketing team at a leading cosmetics company the following summer. My mentor frequently talked about the importance of being "culturally relevant" in each of our markets. My team was also focused on the "increasingly multicultural consumer" in the United States, 
and how best to cater to "her." They had created an ad-hoc "multicultural initiatives" team whose well-intentioned initiatives had consisted only of translating their messaging into different languages and using models of different ethnicities in order to be more "relevant" - a far cry from truly seeing and speaking to their customers in a way that reflected and respected their sociocultural context.

During the internship, I found myself using some of the research methodologies I'd learned in school. I conducted store visits and interviews with my friends whenever I had free time. I would report on my observations and recommendations to my team, who seemed to really value these snippets of consumers' "real lives." It amazed me that they did not have anyone regularly on the ground doing this sort of work, in an effort to understand their customers and competition.

It seemed to me that an anthropological perspective and approach would be really helpful in each of these business cases. I was surprised about the relevance of my academic studies to these business settings and problems - all oriented around needing to understand various consumer segments and experiences.

\section{In Search of Employment}

Then, it was time to find a real job. I vividly remember my first "Information Session" for a leading management consulting firm. Dressed in my business suit, I blended in with the hoard of other eager Princeton seniors desperately trying to make a meaningful impression on the firm's recruiters; however, I felt as though I stood out like a sore thumb. At the sign-in with my economics major friends, I sheepishly marked "Anthropology" as my major, wishing that I could just write "Economics" instead. Would I automatically be put in a different stack than the other more impressive, business-relevant majors?

Then, at the "Networking Session" after the formal presentation, I spoke with one of the senior partners. This was my big chance. After I introduced myself, he asked me my major. When I told him "Anthropology," he responded with, "What's that? Oh, so you've been on some digs?" I managed to mumble a "Yes, but..." before he cut me off: "Then why would you be interested in consulting?"

I was already anxious about the job process and insecure about my major in that context, and his blatant dismissiveness was crushing. Though we continued our conversation, he was looking around the room the entire time. Clearly, he was not interested in me.

I wish that I had known then what I know now: an anthropologist provides an approach to understanding human behavior that is not only unique to any other academic background but that can add tremendous value when applied to business. Businesses at their core are 
conglomerates of people serving other people; people are fundamental to a business's success and survival. Any business hoping to understand how to create the most effective environment for its employees and the most compelling offerings for its customers should be led by and employ anthropologists.

However, at the time, I possessed neither that knowledge nor selfconfidence. Then, his response only confirmed my initial reservations about anthropology: "unemployable" and "irrelevant" to business.

I suppose that I should not have been surprised. In 2012, Forbes Magazine, a leading business publication, ranked anthropology \#1 on its list of the "Top 10 Worst College Majors" (Goudreau 2012). Of all majors, anthropology ranked the lowest in terms of "career prospects" and "expected salary," based on a study conducted by the Center on Education and the Workforce at Georgetown University. The study concluded with the following: "Today's best advice, then, is that high school students who can go on to college should do so - with one caveat. They should do their homework before picking a major because, when it comes to employment prospects and compensation, not all college degrees are created equal" (Carnevale et al. 2012). And, implicitly, don't waste your time majoring in anthropology if you hope one day to be employed and self-supporting.

One year later, anthropology majors received more bad press when Florida Governor Rick Scott announced his intention to cut funding to anthropology programs in favor of more economically viable disciplines like science, technology, engineering and math. On a Florida television show, Governor Scott reportedly said:

We don't need a lot more anthropologists in the state. It's a great degree if people want to get it, but we don't need them here. I want to spend our dollars giving people science, technology, engineering and math degrees. That's what our kids need to focus all their time and attention on, those types of degrees, so when they get out of school, they can get a job. (Goudreau 2012)

Going forward, I tread more carefully in conveying my academic background. In fact, I devised a script for the inevitable "major" question: "I have constructed a curriculum in order to be able to understand, analyze and predict the economic, social, and cultural drivers for consumer behavior." A mouthful, but more impressive I thought to a business recruiter than "Anthropology."

At the Princeton Career Fair, I came in prepared to convey and defend my academic studies in a way that made them seem relevant to business. As I made my rounds to the various consulting firms, I stumbled upon one firm that stopped me in my tracks. Remarkably, ReD Associates marketed themselves on their promotional handouts at the fair as a team of "60 anthropologists, sociologists, economists, journalists, and designers." Anthropologists! I was stunned. Could "Anthropology Major" 
actually be desirable in business?

Their handout continued:

We employ the methods of social science to study human behavior, whether that means understanding why people avoid taking the medications they need or examining how they employ technology in their everyday lives. We develop deep insights into how and why consumers make decisions and use these insights to see the world in more compassionate and complex ways and to identify new opportunities for our clients...We benefit hugely from having a very international staff: Our diversity of perspectives enables us to ask culturally relevant questions and to explore the world in open-ended ways. (ReD Associates 2013)

"Culturally relevant questions" to study "how and why consumers make decisions"? This sounded exactly like my academic interests, only applied to business! To my dismay, however, ReD Associates' recruiting procedures and employment opportunities did not match with my needs. However, my interest was piqued. I wondered if other companies specifically looked for anthropologists.

\section{My Thesis Topic and Methodology}

Back in my room after the fair, I sat down to tackle my goal for the afternoon: decide on a topic for my senior thesis. I had struggled for months hoping for an epiphany on what to focus on. I had several options I was considering, but nothing that was getting me really excited. Racking my brain for a better option, my eyes wandered to the stack of handouts I had gathered at the career fair. ReD Associates was on top. Then, I had my epiphany: what if I do my senior thesis on anthropology and business?

Combing through previous senior thesis titles, I was shocked to find none on that topic. But, are there even anthropologists in business, beyond those at ReD Associates? I doubted it. If there were, surely I would have been exposed to this path at some point during my undergraduate career in anthropology.

Unsure even what to search for ("Business anthropologists"? "Corporate anthropologists"? "Consumer anthropologists"? Did they even still go by "anthropologists" when in business?), I entered "anthropologists in business" into Google. The first item in the search results was a PowerPoint produced by the American Anthropological Association (AAA) entitled "Anthropology for Business" (AAA 2009). Intrigued, I opened the file. The subtitle read: "How Hiring an Anthropologist Will Make Your Firm More Competitive in the New Economy." I was shocked! According to the presentation, major companies including Intel, AT\&T, Walt Disney, Boeing, Microsoft, General Mills, Hallmark, and more all employ anthropologists. 
Though I had been exposed to economic anthropology in several of my Princeton courses, and I had read scholarly articles on the academic study of aspects of business, I had never been aware of the fact that anthropologists worked with businesses outside of academia. Who are these individuals, and how did they end up in commercial contexts? What do they actually do? How is what they do different from what they did in academia? What are their biggest challenges and successes? Does anthropology actually matter in business?

Coming into the topic without any previous exposure, I initially poured over both trade and scholarly articles and books. Throughout this secondary research, I identified names of anthropologists in business, as well as firms that specifically identified as employing anthropological methods and analysis. I explored and analyzed several of these firms' websites to understand how anthropologists represented themselves to potential clients and to the public. I reached out to these anthropologists, asking if they would be willing to contribute to my thesis research, and virtually all agreed!

After receiving IRB approval, I completed twenty interviews with anthropologists who work in business. The research was intentionally oriented to obtain the perspectives of a range of professionals who practice business anthropology across a variety of industries and roles. Interviewees were identified by a review of relevant literature, research on the Internet, their reputation in the industry, their published work, and referrals from other interviewees. The interviewees had varying advanced degrees in anthropology and years of experience in business. In my interviews, I deliberately asked open-ended questions as a means to discover information that I did not think to ask prior to our conversations.

In parsing through the realm of possible approaches to understanding the experiences of anthropologists in business, I realized a shared general experience: all "anthropologists in business" had inevitably transitioned from positions as anthropology graduate students to employees in a business context. I wondered more about what led these anthropologists to pursue a career in business, particularly as all of my personal experience indicated that anthropologists do not usually work in businesses. I asked my informants to tell me more about their career paths.

Moreover, I knew that each of the anthropologists would have had to integrate into their new business roles and contexts. To learn about that transition process, I asked, "How was your transition?" Again, projecting from my own experience as an anthropology major, I assumed that these anthropologists would have had a hard time adjusting to the world of business. After all, I don't believe that anthropology programs educate students in business basics (mine certainly did not). As an anthropology major, I would have no clue about business, other than 
what I had gleaned from my economics-oriented courses and my summer internships. I wondered what was most challenging about their integration, and how their presence was received by other nonanthropologist business people. My own experience at the "Networking Session" caused me to doubt that these anthropologists would be embraced or recognized for their role and potential value in business. After all, anthropologists and business are not a logical or common pairing. I was eager to discover what exactly their contribution to business is, and especially to what extent their anthropological education and training actually impacts that contribution.

I asked my informants, "What is the relationship between your 'anthropological' work (if any) and your academic work?" To be honest, I had no idea in what sense they were anthropologists in business. I could not imagine that they were employing dense anthropological theory or conducting immersive fieldwork in business contexts. However, I discovered that in most cases, my preconceptions proved radically incorrect.

Additionally, I was interested in learning more about their actual work experiences: "What have been your biggest challenges? What have been your most rewarding experiences and successes?" Finally, I probed my informants on their views on the relationship between academia and business, and their engagement (or not) with academia since leaving it. I expected to find essentially no interaction between anthropologists in business and academic anthropology after they departed from academia. What would possibly keep them intertwined? However, my findings problematized my preconceived clear-cut categorical boundaries between academia and business.

I analyzed the content of my interviews in the context of scholarly work my informants have written on relevant topics and themes, other scholarly work pertaining to the field, and anthropological theory from my courses and that my informants referenced as "useful" in their work in business. During this process, I attended to the patterns and themes that emerged out of my conversations, online analysis, and secondary research.

As will become evident in the unfolding description and interpretation of the experience of anthropologists in business that will constitute future articles in this column, the "transition of anthropologists from academia to employment in business" represents not simply a change in status from "academic anthropologist" to "business anthropologist": the anthropologist effectively leaves one culture (academia) to join a new, completely foreign culture (business). The anthropologist's employment and job security depend on fully understanding and successfully integrating into this new foreign culture.

Thus, this series is the outcome of my effort to analyze, interpret 
and understand the experiences of anthropologists working outside of academia in commercial contexts, including the process of their transitions away from their academic backgrounds and life pursuits and their integration into new cultural systems in business. It also provides reflections on my own journey as an anthropologist in business. It is my hope that my series will shed greater light on the application of anthropology in industry, on the experiences of those anthropologists employed in the corporate world, and on the surprising entanglements of apparently different, and perhaps opposed, cultural systems of academia and business.

To lay the foundation for interpreting the stories of my twenty anthropologists in business, I will provide the greater historical and structural context framing and shaping their experiences. What led to the involvement of anthropologists in business? Why didn't they stay within the ivory towers? What kinds of things do anthropologists do in business? The next contribution in this series will set the stage for the forthcoming tales of anthropologists' trials and triumphs in business.

\section{References}

American Anthropological Association. 2009. Anthropology for Businesses: How Hiring an Anthropologist Will Make Your Firm More Competitive in the New Economy. PowerPoint. www.aaanet.org/.../anthbus09.ppt, accessed September 20, 2013.

Carnevale, Anthony P., Ban Cheah and Jeff Strohl. 2012. Hard Times: College Majors, Unemployment and Earnings: Not All College Degrees Are Created Equal. Georgetown Public Policy Institute: Center on Education and the Workforce.

Douglas, Mary, and Baron Isherwood. 1979. The World of Goods: Towards an Anthropology of Consumption. London: Routledge.

Goudreau, Jenna. 2012. The 10 Worst College Majors. Forbes. October11. http://www.forbes.com/sites/jennagoudreau/2012/10/11/the-10worst- college- majors, accessed October 2, 2013.

ReD Associates. N.d. Partners - Mikkel Brok-Kristensen. http://www.redassociates.com/about/partners/, accessed February 1, 2014. 
Elisabeth Powell graduated Phi Beta Kappa and with Highest Honors from Princeton University, where she earned First Prize for her Senior Thesis: "Anthropologists in Business: Teaching Anthropology in the Classroom of Everyday Life." She is a published author and speaker applying her anthropological lens to drive human-centered, global innovation and brand strategy at premier innovation, design and consumer research consultancies. She has added unique value for her clients such as Hilton, Uber, Diageo, Apple, Estee Lauder, Saks Fifth Avenue and Google, and for her firms' cultures and her teammates. Originally from Atlanta, she moved recently to San Francisco from New York to start a new chapter of her own anthropologist in business journey and to explore the natural wonders of the West Coast. 